\title{
GPS RTK技术在采煤塌陷地治理测量中的运用
}

\author{
陈宗成 \\ 山东省鲁南地质工程勘察院(山东省地勘局第二地质大队) \\ 自然资源部采煤沉陷区综合治理工程技术创新中心 \\ DOI:10.32629/gmsm.v3i4.828
}

\begin{abstract}
[摘 要] 当前在我国广衰的土地上,许多煤产区都出现了塌陷的情况,对于采煤塌陷地的治理以及生 态环境恢复也就成为人们日益关注的问题。随着GPS RTK(实时动态测量) 技术的出现,该技术发展至 今已经成为地形测量工程中最常见的技术之一, 对于采煤塌陷地的治理测量, 其也能够发挥出更大的 作用。
\end{abstract}

[关键词] GPS RTK技术; 采煤塌陷地; 地形测量; 测深仪和全站仪

中图分类号：P228.4; P694; TD77 文献标识码：A

\section{GPS RTK技术概述}

1. 1 概念分析

GPS主要以卫星作为核心, 通过无线 电导航定位系统的运用实现数据检测, 该种技术使用中具有全功能、全球性以 及连续性、实时性的特点, 实现对精密三 维坐标、速度以及时间的检测。实时动 态定位 (Real Time Kinematic, RTK) 测量 技术, 通过载波相位观测技术的运用, 可 以在实时差分技术使用的同时进行GPS 测量技术的运用，这一技术作为GPS测量 技术中较为常用的技术形式, 在三维定 位测量中其精度可以达到厘米的状态, 以提高地质测绘的实施性。

\subsection{GPS RTK技术工作原理}

通过对GPS RTK技术的分析, RTK通 过实时动态测量, 可以通过与基准站中 的GPS连接, 实现对地质情况的准确测 试。而且在观测数据中, 通过无线电传输 设备的使用, 能够将数据实时传送到基 准站之中, 之后系统会根据相关的定位 原理对计算数据实施监控, 以保证地质 工程测绘的精确性, 同时在RTK测量中, 通过与GPS技术的融合, 可以实现高效、 可靠的数据传输, 充分满足现代地质工 程测量的需求, 推动地质测绘技术的稳 步发展。

1. 3 GPS RTK技术测量特点

1. 3. 1 效率高
在测量相应的地形工作的过程中, 设站时采用高质量的GPS RTK, 可以对半 径大于 $4 \mathrm{Km}$ 的测区进行测量, 与传统的测 量相比, GPS RTK测量不需要太多的控制 点数量, 其测量仪器不需要多次的转换 位置, 一个人进行操作就能够快速测得 坐标点, 既减少了劳动强度, 又节省了相 关费用, 提高了劳动效率。

\section{3 . 2 测量精度高}

在满足相应的条件下, GPS RTK在适 宜的范围内, 能够达到厘米级的平面精 度, 具有非常高的定位精度。通过使用相 应的处理措施, 高程精度也能够达到厘 米级, 测得相关数据安全可靠, 也没有误 差的积累。

\section{GPS RTK技术应用要点}

\section{1 明确GPS RTK技术要求}

第一, 提高观测卫星图的强度。地质 量测中高强度的卫星图与卫星的数量呈 正比, 因此在坐标测算中, 卫星数量越多, 测量出的数据精确性越强; 第二, 对于测 量人员而言, 整个工作中应该提高自身 的责任心, 掌握GPS RTK技术的使用方法, 结合地质测量的基本条件进行测量工作 的构建, 以保证测量工作的专业性、测量 结果的准确性; 第三, 在数据观测中, 施 工人员应该提高对复核内容的认识。GPS RTK技术存在着实时性高、测量快捷的优 势, 但是由于初始化执行度的限制, 在作
业中若缺少有效复核, 会出现测量结果 不准确的问题。

\section{2 坐标转换参数测量}

在GPSRTK作业之前, 应该控制地区 的静态点, 针对地方坐标系统控制点联 测状态, 及时获取所测位置的GPS点, 而 且也可以实现数据转换的实时性, 为坐 标转化参数的测量提供支持。在坐标转 化参数分析中, 应该选择一致控制点进 行数据精度、密度以及分布状态的分析, 由于坐标的转换参数与求解的质量有着 密切关系, 因此在基准点的坐标选定中, 应该将数据均匀的分布在测区内, 实现 GPS RTK测量结果的精确性。在地质工程 测量中, 应该将数据测区的精准点控制 在3 6点之间, 坐标求解以及参数转换 中, 应该采用差异性的匹配方案, 通过不 同计算方法的运用, 对坐标参数形式以 及检验形式进行分析, 将测量结果的误 差控制在最低范围内, 以实现坐标参数 确定准确性。

2. 3基准站设计技术的运用

通过对地质工程测量状况的分析, 当使用GPS技术进行测量时, 卫星发出信 号到接收机接收信号, 中间会受到电离 层、对流层等多种因素干扰, 导致信号相 对微弱。而在GPS RTK技术使用的过程中, 由于该种检测技术具有超高的电磁波, 这种电磁波的传输距离与接受天线高度 
以及大气的折射存在关联性, 因此在GPS 信号处理中, 为了提高信号接收的有效 性, 应该合理选择基准站的设计位置, 有 效提升数据测量的准确性。

2. 4 作业半径设计技术的运用

对作业半径而言, 主要指移动站离 开基准站的最大距离, 因此半径的大小 与基准站的电台信号传输距离有着一 定的关联性, 在GPS RTK技术使用中, 相 关人员应该对数据测量的速度以及精 确度进行分析, 以保证地质工程测量的 准确性。伴随GPS RTK技术的不断发展 以及测量技术的创新, 地质工程测量中 为了有效扩大作业的范围, 应该合理控 制作业半径, 通常以 $10 \mathrm{~km}$ 内为最佳状态, 若在作业半径选择中受到其他因素的 影响, 需要缩短半径以保证GPS RTK测 量的准确性。

3 GPS RTK技术在采煤塌陷地 治理测量中的运用一以山东某市煤 矿塌陷区为例

\section{1 工程概况}

首先对于山东某市的煤矿塌陷区做 一个详细的调查, 发现该煤矿塌陷区地 势低洼, 常年大面积积水, 而且在5-8月 份的季节里, 该片区域气候潮湿多雨, 水 面雾气较多能见度低, 如果采用常规的 测量方法不太适合。在对山东某市煤矿 塌陷区进行测量时, 要按照相关的技术 标准文件和成图规格及精度的要求。

3. 2 前期准备工作

在作业进行前要做好相关的准备工
作, 要对测量区的相关资料进行收集整 理, 比如控制资料和地形图等, 依据相应 的专业设计书以及测量区的具体实际情 况, 编写相应的测区作业指导书, 对测量 工作提出更加具体和详细的规定, 从而 指导生产作业; 做好作业人员的培训工 作, 经考核合格后才能够上岗作业。

\section{3实际测量工作}

(1) 在进行测图的过程中, 可以有选 择的设置RTK基站。在架设基站时, 需要 遵循一些原则: 尽量避免障碍物和电磁 波信号的干扰, 为了能够良好接受卫星 信号, 应该多避免高压线; 在选点的时候 要确保该点能够连续供电, 满足基准站 的用电需求; 点位要设置在中部的制高 点上, 以便能够覆盖整个作业半径, 有效 的传递电台信号。使用GPS RTK技术在测 量区进行控制测量, 能够随时得到准确 的定位结果, 也能够得到相应的定位精 度, 这就大大的提高了测量作业的工作 效率。在用GPS RTK技术进行控制测量时, 应该要选择视野比较开阔的地方, 从而 接收相应的电台信号, 提高相应地点的 精确度。地理位置比较好的地方有利于 提高GPS RTK控制时的速度, 节省相应的 时间。利用全站仪在RTK控制点进行相关 的测量工作时, 要先对控制点进行相应 的检查, 降低RTK测量过程中受到外界因 素影响的程度。

(2) 在本次测量作业中, 使用 GPS RTK和全站仪组合进行碎部点测量, 通 过两者的优势互补, 可以保证测量的数
据的安全可靠以及定位的精确度。在进 行水下地形测量时, 采用的是GPS RTK和 测深仪组合。与传统水下地形测量方法 相比, 传统水下测量中平面定位和水深 测量是相互独立的, 两者的数据不能够 达到统一, 而GPS RTK和测深仪组合进行 测量就能够有效解决这一类问题, 将平 面定位数据和水深测量数据有机结合在 一起。

\section{4 结束语}

综上所述, GPS RTK技术作为近年 来发展较快的测量技术, 其在现代地形 测量工作中得到普遍的应用。作为一种 实时动态测量技术, GPS RTK能够提供 有关测站点实时的、高精度的三维定位 坐标, 该技术是测量技术发展史上的一 次创新突破。在煤矿塌陷区使用GPS RTK和测深仪、全站仪相组合的测量模 式, 能够在对塌陷区实际的测量中提高 测图的工作效率, 而且对于相关因素带 来的干扰也会减少, 具有极大的经济效 益和发展前景。

\section{[参考文献]}

[1]任春明.GPS技术与谷歌卫星地图 相结合在解决煤矿采煤塌陷等地灾中的 应用[J]. 当代化工研究,2018(12):72-73.

[2]张梅.煤矿测量中GPS技术的应用分 析[J].内蒙古煤炭经济,2019(22): 10-11+31.

[3] 李丽莉.GPS技术在煤矿勘探平 面控制测量中的应用研究 [J]. 能源与节 能,2017(10):27-28+30. 